\title{
More Than a Name
}

\section{A Content Analysis of Name Authority Records for Authors Who Self-Identify as Trans}

\section{Kelly J. Thompson}

With the adoption of FRAD and RDA, the scope of name authority records has broadened from a record supporting an authorized heading to a fuller description of a creator. Meant to help user discovery of resources, these practices are problematic when the record describes an author who self-identifies as trans. In this research, name authority records (NARs) for self-identified trans creators were analyzed. This analysis examined the 375 field for "gender," the contents of that field, and other representations of (trans)gender identities throughout the record. Name authority record creation practices should be examined to ensure that an author's agency to self-disclose their identities is respected.

$\mathrm{T}$ he original purpose of name authority records (NARs) was to give catalogers a framework to record the authorized form of the name of a work's creator to ensure consistency across all instances where the name was recorded in library catalogs. ${ }^{1}$ The record can also contain information allowing a user (or a computer system) to cross-reference names creators may have used over the course of their careers under which other works of interest to the user may be found. ${ }^{2}$ The IFLA Functional Requirements and Numbering of Authority Records (FRANAR) working group first acknowledged an expanded scope for name authority records by including that authorities should also support the user tasks of identifying (disambiguating) and contextualizing an entity. ${ }^{3}$ Following this, with the introduction and adoption of the Functional Requirements for Authority Data (FRAD) and Resource Description and Access (RDA), the original scope of a name authority record was broadened from simply that of a carrier of an authorized heading or access point to a description of an entity with the development of an expanded list of attributes that can be included in name authority records. ${ }^{4} \mathrm{Sev}-$ eral fields have been added to the MARC name authority record format as part of this shift, including the optional 375 field for "gender." RDA 9.7 provides the content standard for descriptive cataloging with these new fields- the rules by which catalogers are guided to record information in these fields. ${ }^{5}$

On the surface, this may seem beneficial. Additional information in a name

Kelly J. Thompson (kelly†@iastate.edu) is Metadata Management and Cataloging Librarian in the Metadata and Cataloging Department at lowa State University.

Manuscript submitted May 26, 2015; returned to author for revision August 24, 2015; revised manuscript submitted September 15, 2015; returned to author for revision February 4, 2016; revised manuscript submitted March 4, 2016; accepted for publication April 1, 2016. authority record could potentially help a user to find all of a creator's works regardless of the name the author used at time of publication or the name under which a user searched. Information included in a "source of information" 670 field could help a researcher to identify the cataloger's sources, such as an author's specific work, or to disambiguate similar name headings. Multiple referenced names in 400 fields could help a user to understand the author's name changes over time or redirect a search using an outdated form of the author's name. However, if NARs are considered from a transgender studies perspective, "an 
emerging theoretical orientation on the nature of gender and gender identity in understanding the lived experiences of transgender and transsexual individuals," these practices can produce problematic results when the record describes an author who self-identifies as trans. ${ }^{6}$

Several librarians have critiqued RDA 9.7 specifically for its use of gender. ${ }^{7}$ The author would like to extend their work to examine how NARs use gender throughout the record, both through use of the 375 field and in other practices that precede the introduction of FRAD and RDA. This research will investigate how (trans)gender identities are being represented using current NAR creation practices, specifically NARs created to describe authors who self-identify as trans. To conduct this investigation, the author analyzed the content of sixty NAR records currently available in the Library of Congress (LC) Name Authority File (NAF) that describe authors who self-identify as trans.

This research investigates whether including an expanded scope of information in a NAR is an inclusive practice, and if it serves the best interests of either authors or library users. Rich self-descriptive information about an author may be found in data stores outside of library catalogs, such as an author's personal homepage, and linked data could be employed to direct our users to this information, as controlled by the creators themselves. Although the authors whose name authority records are considered in this paper are all publicly "out," (which is how it was possible to search for and analyze their NARs), the question is related to how that information is shared, whether by the author or by a third party.

\section{Background}

The word trans is used in this paper to encompass the identities belonging to individuals whose gender identities do not correspond with society's assumptions about their gender identity based on the sex they were assigned at birth. This word is used as an umbrella term to encompass a wide array of transgender and nonbinary gender identities with which people may identify. The term is used here to communicate in a holistic way about people who, as Julia Serrano phrases it, "defy societal norms with regards to gender," and who may identify with any of the many labels for their gender identit(ies), including transgender and labels used for gender identities that fall outside of the assumed gender binary. ${ }^{8}$

Because many people in our society identify as cisgender, the prevailing societal norms of daily life do not always accommodate people who do not experience the social identities of sex and gender as congruent-people who identify with a trans identity. ${ }^{9}$ This is sometimes referred to as cisgender privilege, or the specific rights and benefits that people who identify as cisgender receive, which are not accessible to people who identify as transgender. Hill and Willoughby define transphobia as "the feeling of unease or even revulsion towards those who express nonnormative expressions of gender identity and expression." 10

Because of cisgender privilege and transphobia, people who self-identify as trans are statistically significantly more likely than the general population to encounter discrimination and violence because of their gender identity or expression. ${ }^{11}$ For individuals who self-identify as trans, queer, or with any other type of social identity that carries the possibility of discrimination or violence, the ability to control the disclosure of information about oneself is critical. When information related to an identity that may result in discrimination, harassment, or violence is shared, this is referred to as outing. ${ }^{12}$ People can out themselves, as when people disclose their identity and come out. A person can also be outed by another person. When outing information is shared by someone else, it is unethical unless you are certain the person it is about has shared this information publicly with the intent of others knowing it; if the information was shared privately, the person needs to have explicitly given consent for others to share this information on their behalf for sharing that further to be ethical. Agentic disclosure, or a person's ability to control how information about identity is shared with others, is incredibly important. ${ }^{13}$

One of cataloging's core values is accurate representation of information to enable and improve access. Representations of creators' social identities can work against this goal of accurate and respectful representation, and it can lead to triggering experiences for people with marginalized identities. A poignant example can be drawn from the authority record for Ivan E. Coyote, one of the author's favorite storytellers. Coyote is publicly listed in the NAF (and thus in many library catalogs) as "Coyote, Ivan E. (Ivan E[ . . ] ]), $19[\ldots] . . . " 14$ At the time of this writing, there is no other author by the name Ivan Coyote or Ivan E. Coyote in the $\mathrm{NAF}$, yet two qualifiers are used in the heading: subfield $\$ q$ for "fuller form of name" (Ivan E[ . . ]) and subfield $\$ \mathrm{~d}$ for "dates associated with a name" (typically the author's birth date) (19[ . . . ]-). The Program for Cooperative Cataloging (PCC) Task Group on the Creation and Function of Name Authorities in a Non-MARC Environment states that "authorized access points in RDA are created by combining a name with a defined set of informative qualifiers when available. There are other possible approaches to differentiating one entity name from another. . . Authorized access points are preferably unique in RDA, but it is not required."15 For this NAR, the level of differentiation used is not needed under any of the given guidelines. Coyote has published all of their works under the name Ivan E. Coyote, and has never published under their name assigned at birth. No other authors are listed in the authority file that could be mistaken for this author. Inclusion of this extra name information is not 
respectful of the author's privacy, their self-identification, or bibliographic identity.

The author of this paper would like to cite Coyote themselves in explaining why this is problematic. In a January 2012 Daily Xtra column titled "They' is me," Coyote addresses their perspective on others' inappropriate interest in their name:

A couple of weeks ago I got an email from a young woman, a college student, who claimed that her professor had assigned her entire class a special little assignment, for extra credits, for students who could track down my legal name and bring it to class. This young woman had tried and tried, she said, to find it online, but couldn't, and she really wanted those extra marks. Would I be so kind as to just tell her?

I took a deep breath. I was flabbergasted, skin crawling with chill fingers at how totally creepy this felt, an entire college English or writing or queer studies or whatever class assigned the task of violating my privacy for extra credit at school.

Exactly what educational or literary purpose could my legal name serve, anyway? ...

This leaves me frustrated, and feeling violated, and worried that this will happen all over again this semester, that I will get a new crop of letters from eager students asking me about my legal name.

For those people who use their legal name and have never had any dissonance in their head or life with the name given to them at birth versus the name that feels like their name, well, I am glad for you, I really am. It must be fantastic to have all your ID match your face and your gender and your tits and your birth certificate and what the border guard sees when he looks at you and decides whether or not to let you on the plane. You are lucky.

I am not one of those people. I don't like my legal name, first or last; it doesn't suit me, it never fit...

I changed my name in 1990. That was 22 years ago. Some of my family still call me by my birth name, and I let them do this only because they are my family. I cash cheques and do business and perform and publish and live and fuck and talk to my neighbours as Ivan. Because this is my name. It feels good to be called who I am. . . .

Call us what we wish to be called. ${ }^{16}$

Coyote's words express the core issue at stake here: a person's agency to find a way of being in the world that affirms their identity and sense of self. It is essential that a service, such as cataloging, which is meant to help people to discover resources that will help them in these selfidentification processes, consider this and reflect these identities, and that library systems are designed with a strong effort to reflect people's self-identities with profound respect. We have an opportunity to accurately represent authors as they choose to be known. For librarians invested in working toward gender equity, observing these kinds of misrepresentations within an information system that many trained catalogers do not have permission to edit yields an uncomfortable situation. This research considers how our practices could change to accommodate all authors.

\section{Literature Review}

\section{New Authority for Name Authorities in RDA}

Agenjo et al. wrote, "[The MARC 21] model has shifted from authority records for personal names to the records for persons, which is not a nominal but a long-range issue. In fact, some of the cataloging problems to be solved in the near future will be the combination of persons' attributes with personal names' attributes."17 This shift has been influenced by the Functional Requirements for Authority Data (FRAD), which states that the function of authority control for names should support "not only the task of identification of the entity 'person,' but also the tasks of contextualization." 18 This functional requirement is the impetus for including new fields in the MARC 21 authority record format, such as the 375 field for "gender." The inclusion of a gender field is meant to support the shifting purpose of the name authority record from a documented list of authorized name headings to be used in records, to a record of characteristics of the individual authors themselves. This practice represents a fundamental shift in the theoretical framework. The Descriptive Cataloging Manual Z1 states that "an NAR does not serve as a biographical sketch of a person, nor as an account of the detailed history of a corporate body." ${ }^{\prime 19}$ Yet RDA chapter 9.17 now provides specifically for the provision of "Biographical Information" in an NAR. ${ }^{20}$

The MARC 375 field was not adopted without controversy. The American Library Association (ALA) Gay, Lesbian, Bisexual, and Transgender Round Table (GLBTRT) formed an ad hoc task force, the ALA GLBTRT Task Force on RDA and Gender in Authorities, which provided a formal "comment on RDA's proposed coding of gender in authority records." ${ }^{21}$ Their comment, issued in February 2008, included the following statements:

The current instruction for proposed RDA rule 9.8.0.3.1, 
"Record the gender with which a person identifies using an appropriate term from the list below. female

male

other

not known"

does not acknowledge the fluidity and variety of possible gender identity or identities of an individual over time. It also does not address coding of the variety of gender categories related to bibliographic identities, the individuals who create them, and the relationships among them. (How, for example, would we code George Eliot, a woman writing with a male name, or Barbara Michael, a husband and wife writing novels together under one name?) Furthermore, the limited number of possible values, and the language used for those values is offensive to many people.

This Task Force recommends that RDA not prescribe any coding for gender, and that further study be made of the issues of gender in the context of resource identification and relationships between entities. ${ }^{22}$

Discussion of this statement ensued on the RDA discussion list in February 2008. ${ }^{23}$ The discussion indicated that some voices favored the potential for this information to advance a user's searching ability, and some argued that we could not make exceptions for non-conforming authors when the problems noted did not apply to the "majority" of authors. ${ }^{24}$ Others suggested that it was an important role of the cataloger to respect an author's self-identity, and that this field did not serve that purpose. ${ }^{25}$ Potential use cases for the information were presented, as were problematic aspects of the field's use, such as a limited Library of Congress Subject Headings (LCSH) vocabulary. ${ }^{26}$

The ALA GLBTRT Task Force's recommendation was not accepted, and the rule was codified in RDA 9.7.1.3. As RDA was implemented, this rule became part of current cataloging practice, but not without continued concerns about the usefulness of the MARC 375 field and the RDA 9.7 instructions. Billey, Drabinski, and Roberto identify how the 375 field for "gender," while intending to provide quality bibliographic access, can be problematic when describing something as personal and fluid as gender. ${ }^{27}$ Billey et al. describe how the practices recommended by RDA 9.7 (which prescribes usage for the 375 or "gender" field) lead to descriptive work that "reinforces regressive conceptions of gender identity" and "denies the shifting and contextual nature of gender identities." ${ }^{\text {28 }}$ Furthermore, they explain how controlled vocabularies limited to the gender binary do not leave room for the identities and experiences of nonbinary gendered transfolk. ${ }^{29}$

\section{Putting RDA 9.7 into Practice}

The label for the MARC 375 field ("gender") conflates gender categories and sex categories; the suggested entries of male or female, and nonbinary categories omitted by the suggested terms list such as intersex, are actually sex categories, whereas examples of gender categories might be genderqueer, agender, transgender woman, trans man, woman, man, girl, boy, boi, etc. LC training materials regarding completion of the 375 field also conflate sex and gender categories. ${ }^{30}$ This could be because of people's reluctance to use the term "sex categories," while "gender" as a term feels much safer.

The RDA 9.7.1.3 guidelines instruct one to "record the gender of the person using an appropriate term from the following list: female, male, [or] not known. If none of the terms listed is appropriate or sufficiently specific, record an appropriate term or phrase. Example: intersex, transsexual woman. ... Indicate the source of information."31 The MARC 21 documentation recommends providing a source code for the term used in $375 \$ \mathrm{a}$, to be listed in $375 \$ 2 .{ }^{32}$ The documentation currently provides just two codes: "lcsh," referring to LCSH, and "iso5218," which refers to the International Standard Organization's standard Codes for the Representation of Human Sexes (ISO/IEC 5218:2004). ${ }^{33}$ The values provided in ISO Standard 5218 are "Not known 0 (zero), Male 1 (one), Female 2 (two), Not applicable 9 (nine)." ${ }^{34}$ The documentation for this ISO standard includes the remark "No significance is to be placed upon the fact that "Male" is coded "1" and "Female" is coded "2." This standard was developed on the basis of predominant practices of the countries involved and does not convey any meaning of importance, ranking or any other basis that could imply discrimination. ${ }^{, 35}$ Regardless, this standard ignores people with trans identities and those whose sex assigned at birth may be intersex. This standard is unable to represent the sex or gender identities of a person who identifies with a nonbinary identity, and also creates a hierarchy that privileges maleness over femaleness. Even if catalogers need to work beyond the binary of "female" and "male" to describe an author, often appropriate labels do not exist in the controlled vocabulary we are encouraged to use. ${ }^{36}$

The ALA Library Bill of Rights affirms that libraries are to provide access to resources without regard to "origin, background, or views of those contributing to their creation" and that "a person's right to use a library should not be denied or abridged" because of these characteristics. ${ }^{37}$ The interpretation of this bill of rights, adopted by the ALA Council, further explains that "Article V of the Library Bill of Rights mandates that library services, materials, and programs be available to all members of the community the library serves, without regard to sex, gender identity, gender expression, or sexual orientation." 38 Given that authors are members of the communities that cataloging is meant to 
serve, it follows that metadata and cataloging professionals should decline to adopt standards that reinforce hierarchies of privilege, and exclude already-marginalized groups in our communities. While the usefulness of controlled vocabularies and consistent metadata is invaluable to access and discovery services, it could be argued that describing identities would be better left out of this work.

\section{Critically Engaging the Catalog}

The author previously alluded to the inability of the suggested values and practices related to NARs to accommodate trans identities and experiences. Engaging the vocabulary and "spaciousness" of the catalog through a critical lens is not new. Following in the tradition of the likes of Olsen and Berman, many authors have sought to problematize vocabulary used and improve LCSH's language related to (trans) gender identities. ${ }^{39}$ Most notably missing from LCSH are the terms queer and genderqueer. Drabinski has carried this work further by using queer theory to interrogate not only the library catalog and LCSH. While these vocabularies do change over time, Drabinski asks us to question the possibility of ever creating a truly representational and inclusive controlled vocabulary or catalog, when such an artifact is built by a relatively small number of people at a specific point in time. ${ }^{40} \mathrm{~A}$ few people hold privilege in the creation of an authority file and catalogs: the privilege to represent many other people throughout time and place. Drabinski posits that we educate students in the work of interrogating the catalog as a cultural artifact through a queer theory lens. ${ }^{41}$

\section{Bibliographical Cultural Difference}

Exner's concept of bibliographical cultural difference furthers our understanding of why labeling authors without their input is problematic. ${ }^{42}$ Exner sought to show how North American Indian people's names were represented by those whom he described as experiencing this bibliographical cultural difference. When those who are describing a work or person cannot access the necessary knowledge or background to make an authentic representation, it can lead to inaccuracies, misrepresentations, and silencing of identities. ${ }^{43}$ Bibliographically it makes sense in some instances to include a creator's sequence of names used throughout their life in an authority record (such as if the author has published works under each name). However, especially for people who self-identify as trans, this sometimes is superfluous information that encroaches on an author's right to privacy. Because of the principle of bibliographic cultural difference, a cataloger may not even realize that adding a person's previous name to an authority record can be a faux pas depending on the author's personal navigation of identity. ${ }^{44}$
With the addition of descriptive information to NARs following FRAD and RDA, information about an author is being included in authority records in ways that were not recommended by previous cataloging rules. This information is then publicly available to those who search for name authority records (such as through LC's website), and takes on increasing visibility with the implementation of linked data and other semantic web technologies (changes for which RDA and data models such as BIBFRAME are meant to prepare catalog records.) Including a "gender" or "sex" category in a NAR is a form of outing. As professionals, our intention is provide information that will enable users to locate authors and to disambiguate them from others. However, there are cases when providing this information is harmful to an author and exposes information that is not bibliographically relevant.

\section{Name Changes, Sets, and Sequences}

Writers who experience gender beyond the binary are not the only people in the bibliographic world who have either a series or set of names, as illustrated in the following works. Frank Exner, Little Bear outlines clear language to use when discussing the inclusion of multiple names for an individual in a record, or what Exner deems name sets and name sequences.$^{45}$ According to Exner, a name sequence is a set of two or more "changing . . . names that tell an autobiographical story," or names used sequentially by a person. ${ }^{46}$ For example, Chaz Bono has publicly shared that while his name is now Chaz Bono, his name assigned at birth was Chastity Bono (included in a 400 field in his NAR), which he no longer uses. These names have been used sequentially throughout Bono's life, one replacing the other. In contrast, a name set indicates that two or more names are or were used at the same time by a person. ${ }^{47}$ For example, Matt Kailey's name authority record includes a 400 field (or "see from") for Matthew Kailey. Kailey used both names simultaneously and interchangeably, therefore the names constitute a name set.

Pellack and Kappmeyer identified several ways that name changes can create search problems for library users. Their research investigates the effect on the indexing of scholarly articles after women authors have changed their names for a variety of reasons. ${ }^{48}$ Their technique of investigating how names are recorded in various databases, indexes, and authority files inspired the author's method of searching for name records in the national authority files.

\section{Research Questions}

This research was guided by three main questions:

1. Is the newly introduced and optional 375 "gender" field being used in NARs cataloged with RDA for 
people who publicly self-identify as trans?

2. If the 375 field is present in a NAR, what content values are being used?

3. In what ways beyond the use of the 375 field has gender identity or other outing information been represented in NARs (both on records cataloged using RDA and those using AACR2)?

\section{Method}

The author began collecting sample NARs after encountering NARS for authors/creators who self-identify as trans in the course of regular cataloging work after observing the type, breadth, and depth of information included in these records. Sixty PCC NARs for individuals who are selfidentified trans authors, writers, creators, and/or performers (referred to here collectively as "authors") were analyzed. To collect this set of records, the author generated a list of personal names of authors who publicly self-identify as trans to search for in the LC NAF. The names on the list were drawn from background subject knowledge, compiled from the ALA GLBT Round Table's reading lists, Goodreads, blogs, Amazon, Wikipedia's "Transgender and transsexual writers" page, and Google searches for authors' websites. ${ }^{49}$ The author was able to generate a list of only one hundred names to search in the LC NAF. Twenty-nine personal names on the search list of one hundred were not represented by a NAR in the LC NAF so the set size was reduced to seventy-one. Eleven NARs were eliminated from the test set of seventyone for creators who were born before 1900 or for whom a self-identity of transgender or genderqueer could not be readily confirmed, further reducing the studied record set to sixty NARs. Records for creators born before 1900 were eliminated because of the inconsistency in terminology used before the current period and to support one of the core motivations of this research - to encourage respect of the privacy and safety of living authors. Reviewers of this research have suggested that the "gender" attribute is a valuable one for researchers seeking a specific set of authors (for example, nineteenth-century women writing about civil rights and the suffragette movement), however, the author of this work feels that this potential use case falls outside of the concerns of this paper regarding privacy of living authors with marginalized gender identities currently producing works.

While sixty records may seem like a small sample size out of the entirety of the LC NAF, it was the largest number of records that could be obtained using this method. This could be the result of many factors. It could be because out trans folk continue to experience systemic oppressions that could be prevent them from becoming published authors with NARs. There could be authors in the LC NAF who identify as trans that we do not know are trans because, regardless of profession, many people choose not to out themselves publicly as trans, for a variety of reasons, including because it is private, sensitive information and/or because it is inconsequential to their bibliographic identity and works. All sixty records were accessed between September 19, 2013, and March 13, 2014, using the OCLC Connexion Client cataloging software. After accessing these records, the author compiled selected record elements into a spreadsheet.

Table 1 provides a summary of the elements that were examined related to the research questions. The author first recorded the value in the MARC fixed field 008, position 10 , for "Descriptive Cataloging Rules" used in creation of the record. To investigate research questions 1 and 2 , the author examined whether the 375 field was being used in practice, and if so, what content values were used. In this analysis, the author noted whether the 375 field was used in each NAR. When records included at least one 375 field, the author noted whether there were multiple 375 fields recorded. It was noted whether the entries included "start" and "end" dates. In the content analysis, attention was paid to whether the information included in the records was binarist, or operated under the assumption that there are only two human genders. Notes were recorded for terminology used and whether it was represented in LCSH. The author also recorded whether these 375 fields could reasonably be considered as outing the author as trans.

The author next examined elements related to research question 3, concerning ways that (trans)gender identity is represented in elements other than the 375 in NARs. These elements are also summarized in table 1.

For records that provide multiple names for a person (such as alternate name tracings from 400 fields), the author coded the data to indicate whether these multiple names were name sequences or name sets, determined by consulting the 100, 400, and 500 fields, the bibliographic citations given in the 670 fields, and external resources such as an author's personal webpage.

When a name set or sequence was present, the author coded these instances in one of four ways:

1. alt: When the "see from" (400 field) referred to an alternate form of the same name, the author used alt (example: "Link, Aaron Raz" and "Raz Link, Aaron").

2. yes: If the names given were not alternate forms of the same name, the author coded for whether the inclusion of multiple names was bibliographically significant. For example, if the name was listed as an "earlier form of heading," or if the writer published multiple works and has used each of the names on a work, the inclusion of the "see also" (500 field) reference is bibliographically significant.

3. no: If the writer has never used one of the names given in the record for a published work, and the 
Table 1. NAR Elements Examined in Relation to Research Questions 1-3, Concerning How (Trans)gender Identity is Represented in the MARC 375 Field as well as in Elements Other Than the 375 Field

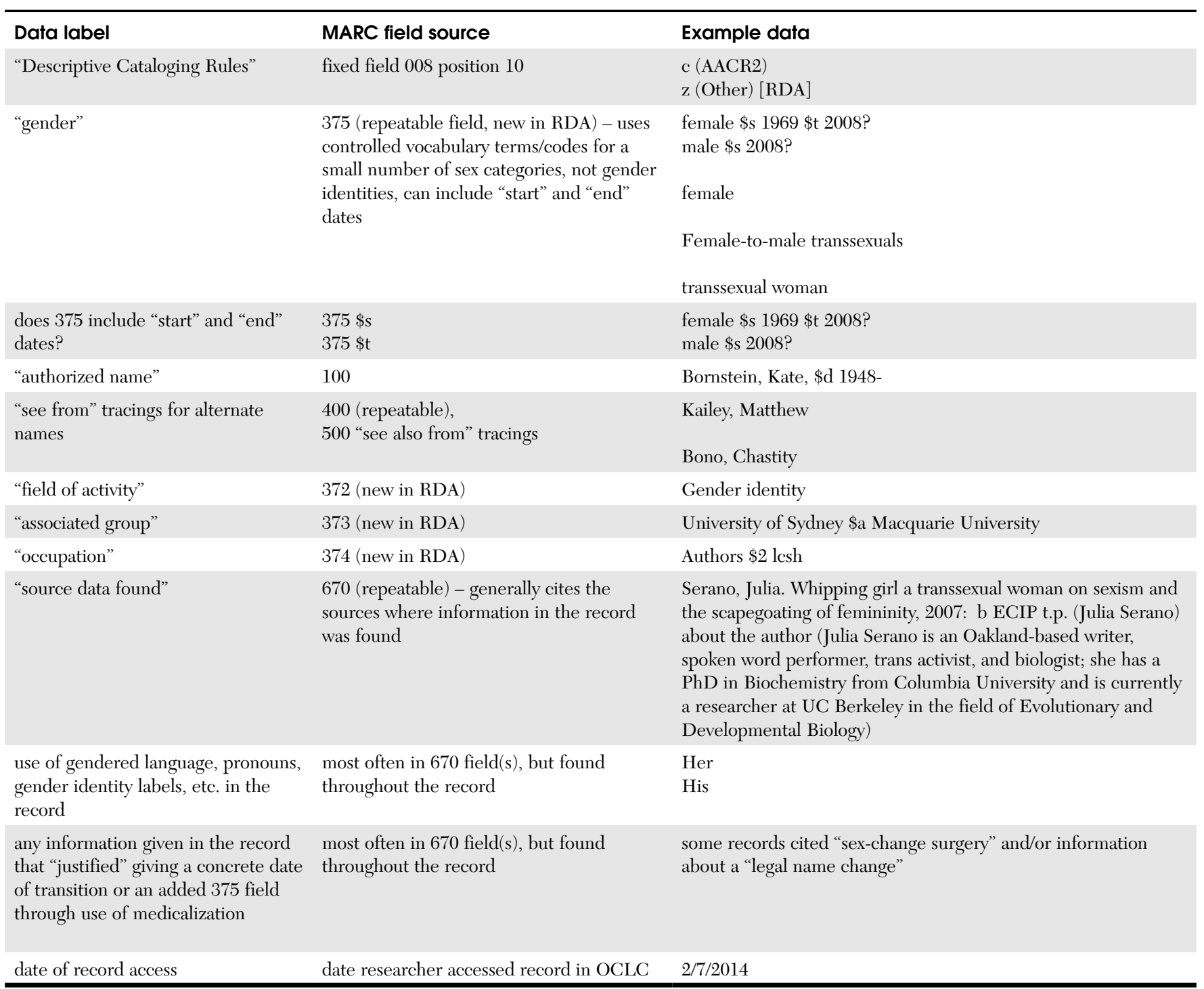

name has never been an "earlier form of heading," it is not bibliographically significant.

4. pen: If the name in the authorized heading is a pen name, and the see also reference (500 field) is the name the person uses in daily life, the author coded the name set as "pen."

When 372,373 , and/or 374 fields were present in the record, the author recorded whether the headings could be interpreted as outing, or as placing a strong emphasis on an author's sexuality. To judge this, an examination was conducted as to whether this information would give the reader information about an author that identified them as trans or as someone with a sexual orientation other than heterosexual.
When a record included 670 field(s), the author coded whether that field contained language about gender or experiences of gender, including those which explicitly outed the writer as trans. It was recorded whether the cited source of this information was self-disclosed by the author (for example, some records cite the author's work, personal website, or an email with the author) or from an external source (such as a publisher or Wikipedia).

Each record was coded for gendered language and pronouns, including inconsistencies in name use or incidents of mispronouning (using incorrect personal pronouns of reference to refer to an author).

Some 670 fields cite both the source of the information included in the record and a quotation from that source. 
The author specifically coded where the quotations in a 670 field provided information meant to support the information recorded into subfields $\$$ s and $\$$ t of the 375 , meant to represent the "start" and "end" dates of the time span the creator identified with each gender. When the quotation included medical information or legal name change information, the record was coded with "medicalized" or "name change" respectively. Records that included both types of information were coded as "multiple types," and records with at least one 375 field with a subfield $\$$ s or $\$$ t but did not "justify" this information in a quotation were coded as "none." Lastly, the author recorded whether it could be perceived that the record as a whole outed the described author as trans via all of the compiled information presented.

\section{Results}

In total, thirty-nine of the sixty records analyzed contained some form of outing information in an area of the record (65 percent). Seven of these were RDA records and thirty-two were AACR2 records. This was manifested through use of multiple 375 fields, inclusion of terms in the 375 field that indicated a trans identity, and through five additional mechanisms that did not require use of the 375 field.

\section{Inclusion of the 375 Field in RDA records (Q1)}

Ten of the sixty records in the test set were coded " $\mathrm{z}$," indicating that they had been created using RDA guidelines. Seven of these records used at least one MARC 375, or "gender," field. The remaining fifty records were coded "c," indicating use of AACR2 rules. Two of the fifty AACR2 records had been updated to include some of the new MARC NAR fields; specifically, they each had two 375 fields added to the record.

\section{Content Values of the 375 fields (Q2)}

Of the nine records containing at least one 375 field, three records provided a single 375 field. The other six records included more than one 375 field, which means that multiple labels for sex or gender identities were given. Among the nine records with 375 fields, there were seventeen total 375 fields (an average of 1.9375 fields per record with 375 field(s)). Three records contained one 375 field, four records contained two 375 fields, and two records contained three 375 fields.

A 375 field may include binary "start" and "end" dates using the subfields $\$$ s and $\$$ t, per the MARC format guidelines. ${ }^{50}$ The $\$$ s and $\$$ t subfields were used in five of the records with 375 fields ( $>50$ percent of records with 375 fields). Of the six records with multiple 375 fields, only one lacked "start" and "end" dates. Three of the records with $\$ s$ and $\$$ t fields were cataloged using RDA and two of the records were cataloged using AACR2. These results are summarized in table 2.

Nine of the NAR records contained at least one MARC 375 field, and six of these records used only "female" or "male" as categorical terms. Three records used terms that indicated a trans identity. Two of these used three successive 375 fields to indicate that a gender identity shift had occurred by using "female" and "male" labels and "start" and "end" dates plus an LCSH term to indicate trans status. "Female-to-male transsexuals" and "male-to-female transsexuals" were the specific terms used in these two records. One record contained a single 375 field with the term "transsexual woman."

In total, from nine records with at least one 375 field, seven contained information in the 375 field(s) that could be perceived to be outing (78 percent of records with at least one 375 field). Five of these were RDA records (71 percent of RDA records with 375 fields), and two were AACR2 records (100 percent of AACR2 records with 375 fields). A summary of the use and content values of the 375 fields can be found in table 2 .

\section{Other Representations of Gender and Instances of Outing in the NAR (Q3)}

There are five mechanisms through which gender and/or outing information have been represented in NARs beyond use of the 375 field: (1) inclusion of superfluous qualifiers in the authorized heading, (2) alternate names given in 400 fields or "see from" references, (3) use of gender or sexuality terms in the $37 \mathrm{X}$ fields $(372,373$, and 374$)$, (4) use of pronouns in the 670 or "source of information" field, and (5) disclosure of personal information unrelated to bibliographic access in the 670 field.

\section{Unnecessary Qualifiers in the Authorized Heading (100 field)}

As noted in the introduction, one record in the set $(<2$ percent) included a qualifier in the name heading that is not part of the author's name as currently used for publication and is not necessary to disambiguate the author from another with the same or a similar name.

\section{Name Sets and Name Sequences (400 fields)}

Of the sixty records in the test set, thirty-four records (57 percent) provided multiple names for an author. These are recorded in one or more 400 fields, which are used as "see from tracings." These fields are used to automatically refer a searcher to the authorized form of an author's name, which 
is to be used on all records for their work, regardless of the name used when any given work was published.

Of the thirty-four records with multiple names given, twenty-four had name sequences (40 percent of the sixty record set, 71 percent of those with multiple names) and ten had name sets (17 percent of the sixty record set, 29 percent of those with multiple names). The author identified four general types of alternate names listed: pen names, alternate forms of the same name, an alternate name that is bibliographically significant, and inclusion of a sequence of names used by a person during various points in time that is not bibliographically significant. The frequency of these types of name sets and sequences is given in table 3 (some name sets/sequences fall under multiple of these four categories). This last type is the form identified in this work as particularly problematic: name sequences or sets that are not bibliographically significant. There were ten records with this type of multiple name listing (17 percent of the 60 record set, 29 percent of records with multiple names).

\section{$37 X$ Fields $(372,373,374)$}

All MARC 37X fields are optional and repeatable. Eleven of the records analyzed included at least one $37 \mathrm{X}$ (including 375 fields). While these fields are optional, they have been used with a fair amount of frequency. Nine out of ten RDA records in the test set included at least one 37X field (90 percent of RDA records.) Seven records used the 372, 373, and/or 374 fields. All of these records were cataloged with RDA (70 percent of RDA records.)

Beyond the 375 or "gender" field, the author observed three other new MARC authority fields present in the NARs in the sample set used to present outing or sexualized information. These are the MARC 372 for "field of activity," 373 for "associated group," and 374 for "occupation." These fields were sometimes used to share information that could be read as outing a person's sexual orientation or gender identity, or shared information that was related to an author's sexuality in a way that did not seem relevant to the work being presented. While the outing information shared in the sample set primarily regarded sexual orientation, not gender identity as the remainder of this paper focuses on, given that these fields have been used to share sexual orientation identities, the possibility exists for them to also be used to represent gender. These additional $37 \mathrm{X}$ fields were each found on seven records in the sample set. All seven were cataloged using RDA. Table 4 summarizes the author's observations of these fields.

Four records contained optional 372 fields for "field of activity." Of these, two fields had information that could be seen as outing (one sexual orientation and one gender identity) and one field recorded information that focused on the author's sexuality in a way that did not hold bibliographic significance. Two records had optional 373 fields for "associated group," and one provided information that was outing (sexual orientation). Six records had optional 374 fields for "occupation," and one provided information that was outing (sexual orientation).

\section{Pronouns and Disclosure of Personal Information Unrelated to Bibliographic Access in the 670 Field(s) or "Sources Found"}

The 670 field, or "sources found," is used to cite the sources of the information recorded in the NAR. Often the information included in this repeatable field is used to "justify" the 
Table 3. Records with Multiple Names Listed for an Author

\begin{tabular}{|c|c|c|c|}
\hline & No. of Records & $\begin{array}{l}\% \text { of Records } \\
\quad(n=60)\end{array}$ & $\begin{array}{c}\% \text { of Records with } \\
\text { Multiple Names }(n=34)\end{array}$ \\
\hline Multiple names given & 34 & 57 & 100 \\
\hline sequences & 24 & 40 & 71 \\
\hline sets & 10 & 17 & 29 \\
\hline not pen or alt but bibliographically significant & 16 & 27 & 47 \\
\hline not bibliographically significant ${ }^{*}$ & $10^{*}$ & $17^{*}$ & $29^{*}$ \\
\hline alternative form of one name & 7 & 12 & 21 \\
\hline pen name & 1 & 2 & 3 \\
\hline
\end{tabular}

* indicates information shared perceived to be problematic in practice.

Table 4. Use of Optional 37X fields in NARs

\begin{tabular}{|c|c|c|}
\hline & $\begin{array}{l}\text { No. of } \\
\text { Records }\end{array}$ & $\begin{array}{l}\text { No. of } \\
\text { Fields }\end{array}$ \\
\hline $37 X$ fields $(372,373,374$, and/or 375 ) & 11 & 35 \\
\hline Non-375 fields $(372,373$, and/or 374$)$ & 7 & 18 \\
\hline 372 ("field of activity") & 5 & 6 \\
\hline outing information (sexual orientation) & 1 & 1 \\
\hline outing information (gender identity) & 1 & 1 \\
\hline reference to sexuality & 1 & 2 \\
\hline 373 ("associated group") & 3 & 6 \\
\hline outing information (sexual orientation) & 1 & 1 \\
\hline 374 ("occupation") & 6 & 6 \\
\hline outing information (sexual orientation) & 1 & 1 \\
\hline 375 ("gender") & 9 & 17 \\
\hline outing information (gender identity) & 7 & 15 \\
\hline
\end{tabular}

information about the person's medical history using often-problematic words/ phrases such as "transitioned," "genderidentity disorder," "sex-reassignment surgery," or "sex-change operation" $(n=6$, 10 percent). These terms are outdated, generalized, and objectify transfolk, and stray from the NAR's purpose of helping catalog users find resources created by a specific individual.

The 670 fields cited information from a variety of sources, such as the author's work ( $n=17,28$ percent), a publisher of the author's work $(n=9,15$ percent), and Wikipedia ( $n=6,10$ percent). Only three records cited an author's personal website ( $n=3,5$ percent), and just one cited direct communication with the author ( $n=1,2$ percent). Of the thirty-six records that contained outing contents of other fields. All of the sixty records in the sample set included at least one 670 field. The 670 field is most commonly used to cite the work in which the form of the author's name was found. Typically, this is a work being cataloged for which a controlled name heading is needed, and thus the NAR was created. However, in the case of NAR records for authors who are trans-identified, this research found that information is often added to the 670 field that would not be included in the NAR for a cisgender author. Table 5 summarizes the findings related to 670 fields.

In the sample record set, thirty-six of sixty records $(60$ percent) contained information in the 670 field that explicitly outed the author as trans. This was done through using language such as "transgender," "transsexual," or "trans" ( $n=23,38$ percent) by describing changes in names or pronouns used with inferences to gender identity, or by sharing information in the 670 field, there were forty 670 fields in total with outing information (some records had multiple 670 fields with outing information). Some records cited the source of outing information from both the author (either their $\operatorname{work}(\mathrm{s})$, personal website, or direct communication) and another source, thus the total of forty outing instances across thirty-six records. Of the forty instances, twenty-one cited the author as the source of information (53 percent of outing 670 fields), while nineteen cited another source, such as a publisher or Wikipedia (48 percent of outing 670 fields). Table 6 summarizes the types of information sources cited. While 60 percent of records in the sample set $(n=36)$ contained information that outed the author as trans, only about half of those ( $n=21,58$ percent of outing records, 35 percent of the total record set) cited the author as a source of information. 
In addition to including outing information, many records used gendered language when a gender-agnostic term is preferable $(n=22,37$ percent), used "mosaic" pronouns (pronouns for the same person that correspond to multiple different genders, which can sometimes be consensual but are often seen as nonaffirming of identity) $(n=$ 11, 18 percent), used outdated or incorrect pronouns ( $n=9,15$ percent), or included nonbibliographically significant pronouns to indicate authorship of a work (a practice not required by the cataloging rules) ( $n=6,10$ percent). See table 7 for a summary of these results.

Nine (15 percent) of the records analyzed included information related to a person's medical history or a change in name or pronouns to justify the inclusion of multiple 375 field(s) or subfields $\$$ s and $\$$ t "start" and "end" dates. This information was often recorded as one of only two sex/gender categories (male or female), which does not reflect many people/authors' lived experiences. Of these, six records defined trans-ness or gender transitions using information about surgery or medical histories (10 percent). Six records mentioned a name or gender identity change (10 percent), sometimes including the phrase "legal name change," or a change in the personal pronouns used by an author. Of the six records in the sample set with multiple 375 fields, three used binarist medical transition or name change information to "justify" this information ( 3 of 60 records, 5 percent; 3 of 6 records, 50 percent). These results are summarized in table 8.

\section{Discussion}

\section{Inclusion of 375 fields (Q1)}

As shown in this analysis, the new MARC 375 field for "gender" is being included in NARs cataloged using RDA. This field appeared in 70 percent of RDA NARs in the sample set $(n=7)$ and was the only new 37X field added to any updated AACR 2 records that were examined $(n=2)$. Future research is needed to see how the adoption of this field fares over time, and to perform comparative analyses of NARs for authors who a
are cisgender.

\section{Content Values of 375 Fields (Q2)}

The 375 field specification also includes subfields $\$$ s and $\$$ t, for "start" and "end" dates related to a particular biological sex, gender, or another identity label. ${ }^{51}$ These subfields were used in five out of nine records with 375 fields in the test set (56 percent of records with 375 fields, 8 percent of the record set). Including a "start" and "end" date for a gender identity or sex category reinforces the problematic ideology of gender as a binary in which a person might only move from point $\mathrm{A}$ to point $\mathrm{B}$, rather than gender as something that is constantly performed, constructed, and fluid. While the purpose for developing these subfields was not uncovered in this research, instructions in the MARC standard documentation for the 375 field and instructions provided in LC training both include examples of using these subfields for the purpose of delineating the gender of transfolk and provide no other use cases for these fields in the context of a NAR for a personal name. ${ }^{52}$ Like many microaggressions, one can assume that these decisions came from a wellintentioned place: by representing the changes in identities 
Table 7. Inconsistent Gendered Language in 670 Fields by Type

\begin{tabular}{|c|c|c|c|}
\hline Records with Inconsistent Gendered Language: & No. of Records & $\begin{array}{l}\% \text { of Records that } \\
\text { Contain Inconsistent } \\
\text { Gendered Language } \\
(n=22)\end{array}$ & $\begin{array}{c}\% \text { of All Records in } \\
\text { Sample Set } \\
(n=60)\end{array}$ \\
\hline use mosaic pronouns in non-affirming way & 11 & 50 & 18 \\
\hline use old or wrong pronoun & 9 & 41 & 15 \\
\hline
\end{tabular}

Table 8. Use of 670 Fields to Indicate Trans Status Using Medical or Name Change Information

\begin{tabular}{|c|c|c|c|}
\hline Records with Medical or Name Change Information & No. of Records & $\begin{array}{l}\% \text { of All Records in } \\
\text { Sample Set }(n=60)\end{array}$ & $\begin{array}{l}\% \text { of Records with } \\
\text { Medical Transition } \\
\text { or Name Change } \\
\text { Information }(n=9)\end{array}$ \\
\hline $\begin{array}{l}\text { Record indicates trans status with medical transition or name } \\
\text { change information }\end{array}$ & 9 & 15 & 100 \\
\hline medicalization or surgery for transition date "justification" & 6 & 10 & 67 \\
\hline have multiple 375s and justify w/ medicalization or name change & 3 & 5 & 33 \\
\hline
\end{tabular}

a person has had over the course of their life and giving the cataloger approximate time periods to use, we can represent authors as they choose to be known, rather than as they may have been known at the time a given work was published. This potentially helps users find related resources by referring them to a work under a name that they might not have known. However, gender identities are fluid and complicated, and do not instantaneously change simply with the start or stop of a prescription, the legal process of changing a name on official documents, or on the date of any kind of surgery, should an individual have enough financial and social privilege to access that type of health care or legal intervention. Identities are formed and re-formed over lifetimes, and often in an individual's life there are many transition processes, not a single monolithic transition. The author believes that this experience is erased by delineating years of identity changes, unless these dates have come directly from the author who is being described by the NAR and they have given their consent to share the information.

Limiting entries in the 375 field to values contained in a controlled vocabulary, such as LCSH or ISO 5218:2004, Information Technology Codes for the Representation of Human Sexes, constrains the record's ability to accurately and respectfully represent the identities of the authors it describes. As modern sociological research has indicated, human genders and sexes are socially constructed categories and exist outside of the binaries of simply "woman" and "man" or "female" and "male." "533 Gender identities are socially constructed, constantly performed, and tremendously fluid. ${ }^{54}$ These are not just theories, but the real identities and lived experiences of people across social groups and stratifications. Honoring this will require finding creative ways to incorporate authors' own words and labels, with their consent.

In discussing the creation of adequate controlled vocabularies, Drabinski argues that replacing problematic subject headings in national authority vocabularies may be useful and needed, but there are problems in imposing our view of identities and our language on people who lived in a different time or different cultures or circumstances as ourselves. ${ }^{55}$ She also argues that a reading of the NAF through a queer theory lens could yield a conclusion that a controlled vocabulary describing people and identities can never be complete or perfect simply because of the nature of how it is constructed. ${ }^{56}$ One way to work with these systems, she writes, is to engage with them through a queer lens, asking, "Whose voices are missing here? Whose are represented? Who has the power in this situation?"57 If we apply this thought framework to NARs, we might conclude that if it is indeed important to include these identities in a record, it would be better left to an individual to decide and to carry out on their own terms. Further research is needed to assess whether the terms currently recorded in these records are congruent with the labels with which the authors themselves identify in a system where they can edit their own authority record, similar to the ORCID research identifier system.

A few of the NARs analyzed contained outdated information in the 375 field. Gender identity is fluid and often changes throughout an individual's lifespan, and continuing to update the NARs to reflect these changes is not easy 
in the present closed system. While most current library systems lack the capacity to use this data at present, the potential future use of this data becomes problematic when maintenance is not feasible because of several constraints.

\section{Other Representations of Gender Beyond the 375 Field (Q3)}

The third research question was whether additional representations of gender were included in NARs other than the use of the 375 field. The author observed five mechanisms through which gender is represented or outing information is shared in NARs beyond use of the 375 field. This shows that regardless of whether the 375 field is used, current cataloging practice employs other mechanisms through which this private and sensitive information is being shared.

As noted in the introduction, one of the records analyzed ( $<2$ percent) included a qualifier in the name heading that was not part of the author's name as currently used for publication and was not necessary to disambiguate the author from another with the same or similar name. Inclusion of this superfluous name information is not respectful of the author's self-identification. The PCC Task Group on the Creation and Function of Name Authorities in a NonMARC Environment's report argues that a URI or author identifier could do a better job of disambiguating records than these subfields, while being compatible with a linked data future. ${ }^{58}$ As the report suggests, to do this requires moving beyond the legacy parameters of the "record" and involves rethinking many of our current systems. ${ }^{59}$ This research supports the usefulness of this suggestion.

While 60 percent of records in the test set contained information that outed the author as trans $(n=39)$, only about half of those $(n=21,35$ percent of the total set of records) cited the authors themselves as the source of that information. The practice of outing authors via any source but their own voice removes their personal agency to selfdisclose, and the author appeals to catalogers to consider this when examining cataloging practices. Including pronouns that may not be accurate representations of the pronouns an author chooses to use can be nonaffirming to an author's gender identity and are better left out unless the pronouns of reference can be confirmed from a source that captures the author's own voice.

Some records included information that medicalized gender transition, perhaps as a form of "proof" that it had occurred. This act denies and erases the lived experiences of those transfolk who chose not to or cannot obtain medical intervention in their identity formation processes. Additionally, documenting deeply personal information that relates to medical histories or name changes is not respectful of an author's right to privacy, and violates the information sharing ethics on which laws such as HIPPA protections have been built. Further research is needed to compare the amount of information, especially that of a personal nature, that has been provided in name authority records for authors who are trans versus those who are cisgender.

\section{Linked Data and Self-Description as Potential Solutions}

Linked data provides a solution for ensuring consistent and uniquely identifiable data. Rather than including fixed, selected data in a record, the authority record could connect a name (or series or set of names) to a URI. Links could be established to the author's works and other authoritative sources of information over which the author may have more control. Names would not need to be unique or disambiguated to create a unique heading, as the URI link would serve the purpose that the heading formerly had.

The author proposes a shift in thinking about name authorities from a system where catalogers are the authoritative voice to one where authors have the agency to selfdescribe their own experiences to whatever extent they wish. An example of a system with widespread adoption that does this is the ORCID unique researcher identifier system. ${ }^{60}$ ORCID iDs have been adopted in practice by many systems, such as those that track scholarly research outputs, systems for tracking alternative research metrics, several journal article publishing platforms, and in the application processes for government granting agencies. ORCID functions on the premise that authors create their own authority record, include the information that they choose to disclose (and control levels of privacy for pieces of information on a very granular level), and link to their varied scholarly works, affiliations, and other researcher identifiers to establish their bibliographic identity as an author and researcher.

If name authorities continue as a closed system, catalogers can work to improve the system by working through the lens of transgender theory and examining the bibliographic significance of including specific information. Some questions to help guide this practice include the following:

- Is there potential for this information to harm the author through outing or violating the right to privacy?

- Is there an indication that the author consents to having this information shared publicly?

- Will including this information help a library user in the search process?

\section{Outing, Privacy, and Safety Issues}

The argument for including fields such as the 375 in NARs to enhance search and retrieval possibilities is not strong enough to justify the inclusion of such sensitive information in a publicly accessible database. While our current library systems lack the capacity to use this data, the use of this 
data to search for authors or works could be quite problematic in future implementations. Not only do these new and current practices tokenize and "other" those whose gender identities fall outside of the traditional cissexist binary, but imagine the response if RDA suggested the addition of a race or religion category to the name authority record. Other legally protected classes such as race, religion, and sexual orientation are not addressed by the RDA attribute recommendations. Gender identity should be conceptualized in the same way. Gender identity is a protected class in many states, and should be given the full weight of respect as any other when it relates to talking about and potentially labeling other people. This research lends support to the recommendation to not include the 375 field in NARs unless communication and permission has been received from the author. If an authority record creator needs to justify information given in other fields in a record with a 670 field, only information pertinent to the work in hand should be included, and drawn from the author's work or personal communication.

\section{Inability of the Suggested Values and Cataloging Practices to Accommodate Trans Identities and Experiences}

Although writers who self-identify as trans in some way are not unique in the bibliographic world in having either a series of names that they use or name sets that they use, we as a community of practice should examine how bibliographic name authority descriptions, particularly when using RDA, do not necessarily treat these authors equitably as compared to their peers who identify as cisgender. It is worth considering as catalogers whether the current policies governing when to create a new name authority record are still conceptually sound when we acknowledge that identities are fluid and change over time. The practice of filing under latest-entry is only standard for personal names; serials catalogers have grappled with this concept and settled on successive entry as a better solution. Under this model, changes in the names of corporate bodies, conferences, and titles of serials lead to new authority records that link previous and/or successive names or titles. This is also true for rules governing bibliographic records for new editions of works (new editions get new bibliographic records.) How would this look in practice for personal names? What does that mean for NARs in their role as entity descriptions versus authorized lists of headings? Catalogers could consider using URIs or author IDs as part of a practice of using linked data to solve part of the issue of requiring an authorized form of name. Name changes could be recorded in an external location (an author's personal website, Wikipedia, etc.) while the URI is all that is needed to link that additional information to the bibliographic database.

\section{Conclusion}

Previous literature has critiqued RDA 9.7 and the use of the MARC Name Authority Record 375 field in relation to the problematic representation of gender. ${ }^{61}$ This field was included in 70 percent of RDA NARs analyzed for this research, and was the only new authority field added to any of the AACR2 records in the test set. Analysis of the contents of these 375 fields confirms that its use is frequently outing in practice when used to describe authors who self-identify as trans.

Additionally, this research has shown that there are other areas of the NAR format besides the 375 field that warrant further scrutiny from the cataloging community. According to the results of this investigation, MARC 400 and 670 fields contain outing information in both NARs with 375 fields and those without. This finding raises practical and ethical concerns for catalogers, including risk of inaccurate or outdated representations of creators' identities; outing, privacy, and safety issues; and the inability of the suggested values and cataloging practices to accommodate trans identities and experiences.

Catalogers can work as allies to communities of people who experience oppression, discrimination, and often violence as a result of others' perceptions of their identities, and in particular, gender identities; this work is supported by the core principles of the Library Bill of Rights. ${ }^{62} \mathrm{We}$ are in a unique position as catalogers to do this work, and to open the doors for all authors to self-describe in authentic, empowered ways, and to assist users in discovering and accessing their work.

\section{References and Notes}

1. Library of Congress, Network Development and MARC Standards Office, "Introduction. Scope of the Authority Format" in MARC 21 Format for Authority Data (Washington, DC: Library of Congress, 1999 edition (section revised October 2009)), https://www.loc.gov/marc/authority/adintro.html.

2. Library of Congress, Network Development and MARC Standards Office, "MARC 21 Format for Authority Data" (Washington, DC: Library of Congress, 1999), https://www.loc.gov/ marc/authority; Special Libraries Cataloguing, "MARC Authority RecordCheatSheet,"2011, www.special-cataloguing .com/node/1395.

3. Bob Thomas, "Name Disambiguation—Learning From More User-Friendly Models," Cataloging \& Classification Quarterly 49 no. 3 (2011): 223-32, http://dx.doi.org/10.1080/01639374 .2011.560834.

4. Ibid.; Xavier Agenjo, Francisca Hernández, and Andrés Viedma, "Data Aggregation and Dissemination of Authority Records through Linked Open Data in a European Context," Cataloging \& Classification Quarterly 50, no. 8 (2012): 803-29. 
5. Library of Congress, Network Development and MARC Standards Office, “375-Gender (R)," in MARC 21 Format for Authority Data, 1999 ed., rev. 2009 (Washington, DC: Library of Congress), https://www.loc.gov/marc/authority/ ad375.html.

6. Julie L. Nagoshi and Stephan/ie Brzuzy, "Transgender Theory: Embodying Research and Practice," Affilia: Journal of Women and Social Work 25, no. 4 (2010): 431-43.

7. Amber Billey, Emily Drabinski, and K. R. Roberto, "What's Gender Got to Do with It? A Critique of RDA 9.7," Cataloging \& Classification Quarterly 52, no. 4 (2014): 41221, http://dx.doi.org/10.1080/01639374.2014.882465; "GLBTRT Task Force on RDA and Gender in Authority Records," GLBTRT News, 2008, www.glbtrt.ala.org/news/archives/20.

8. The term gender binary is the assumption that there are only two human genders: women and men, even though in reality two categories do not represent the genders of all people. It includes cultural assumptions that a trans person would experience a transition only once, and in doing so, simply move from one side of an imagined (and false) gender spectrum to the other. While some people who are trans experience their gender identity and any transitions they may access in this way, many do not. Charlie McNabb explains, "Nonbinary identities are those that fall outside of the traditional binary 'man' and 'woman' gender categories. Nonbinary folks can be somewhere between man and woman, a mixture of both, or may identify completely separately from these categories. Nonbinary people can also move between genders or have no gender at all. The term 'nonbinary' is used as an umbrella term . . . individual nonbinary folks may have any number of other identity terms that they prefer." [Charlie McNabb], "Nonbinary Gender Identities in Media: An Annotated Bibiography” (annotated bibliography, 2015), www.ala.org/ glbtrt/sites/ala.org.glbtrt/files/content/professionaltools/Non binary\%20Gender\%20Identities\%20in\%20Media\%20Anno tated\%20Bibliography.pdf. See also Julia Serrano, "Regarding Trans* and Transgenderism," Whipping Girl (blog), August 27, 2015, http://juliaserano.blogspot.com/2015/08/regarding -trans-and-transgenderism.html.

9. Cisgender people experience their gender identity in ways that conform to cultural expectations about how people assigned their biological sex at birth should exist in the world. For example, a person who was assigned female at birth (biological sex), and self-identifies as a woman (gender identity), might identify as a cisgender woman. A person who was assigned female at birth (biological sex), and self-identifies as a transman, as genderqueer, or as a man (gender identities) might identify as transgender.

10. Daryl B. Hill and Brian L. B. Willoughby, "The Development and Validation of the Genderism and Transphobia Scale," Sex Roles: A Journal of Research, 53, no. 7-8 (2005): 531-44.

11. National Coalition of Anti-Violence Programs, "Lesbian, Gay, Bisexual, Transgender, Queer, and HIV-Affected Hate Violence in 2013: A Report from the National Coalition of
Anti-Violence Programs," (New York: New York City Gay and Lesbian Anti-Violence Project, 2014), www.avp.org/storage/ documents/2013_ncavp_hvreport_final.pdf.

12. “Tips for Allies of Transgender People," GLAAD, accessed August 25, 2015, www.glaad.org/transgender/allies.

13. The author has used the pronouns "they," "them," "their," "themselves," and "theirs" as third-person singular pronouns throughout this work in two types of instances. The first is to affirm the pronouns used by specific individuals consistent with their gender identities. The second is as a practice of using language uninhibited by gender when referring to a non-specified person implicitly or explicitly of any gender. For additional resources on this language construction, please see Zena Sharman, "Singular They Reading List," accessed October 4, 2013, http://ivancoyote.tumblr.com.

14. The author has redacted personal information from this name heading in this manuscript for privacy. The full name authority record cited here can be found on LC's webpage at https:// lccn.loc.gov/n2001029640.

15. Program for Cooperative Cataloging, PCC Task Group on the Future of Name Authorities in a Non-MARC Environment, "Report for PCC Task Group on the Creation and Function of Name Authorities in a Non-MARC Environment," 2013, www.loc.gov/aba/pcc/rda/RDA\%20Task\%20 groups\%20and\%20charges/ReportPCCTGonNameAuthInA_ NonMARC_Environ_FinalReport.pdf.

16. Ivan E. Coyote, “'They' Is Me: Call Us What We Wish to Be Called,” Daily Xtra, January 11, 2012, www.dailyxtra.com/ vancouver/they-is-me-4408.

17. Agenjo, Hernández, and Viedma, "Data Aggregation and Dissemination," 824.

18. Ibid, 805.

19. Policy and Standards Division, Library of Congress, "Z1. Name and Series Authority Records-670 Source Data Found," Descriptive Cataloging Manual, accessed September 1, 2015, www.loc.gov/catdir/cpso/dcmzl.pdf.

20. Joint Steering Committee for Development of RDA, "9.17 Biographical Information," in RDA: Resource Description and Access (American Library Association, Canadian Library Association, and Chartered Institute of Library and Information Professionals (CLIP), 2009).

21. "GLBTRT Task Force on RDA and Gender in Authority Records."

22. Ibid.

23. "RDA Listserv (RDA-L) Email Discussion February 12, 2008-March 3, 2008," Joint Steering Committee for Development of RDA (JSC), Library and Archives Canada, 2008; J. McRee Elrod to RDA-L mailing list, February 12, 2008, https://www.mail-archive.com/rda-1\%40listserv.lac-bac.gc.ca/ msg01607.html.

24. Ibid.

25. Ibid.

26. Ibid.

27. Billey et al., "What's Gender Got to Do with It?," 412-21. 
28. Ibid, 412,414

29. Ibid., 414, 417, 420; "GLBTRT Task Force on RDA and Gender in Authority Records," www.glbtrt.ala.org/news/ archives/20

30. Ana Lupe Cristán, "RDA Special Topics: RDA Elements in Name Authority Records (NARs): MARC 21 Fields," (presentation, Policy and Standards Division, Library of Congress, Washington, DC, 2012), www.loc.gov/aba/rda/source/ special_topics_elements_NARs.ppt.

31. Joint Steering Committee for Development of RDA, "9. Identifying Persons," in RDA: Resource Description and Access (American Library Association, Canadian Library Association, and Chartered Institute of Library and Information Professionals (CLIP), 2009).

32. Library of Congress, Network Development and MARC Standards Office, "MARC 21 Format for Authority Data."

33. International Standards Organization/ International Electrotechnical Commission, "Information Technology_Codes for the Representation of Human Sexes (ISO/IEC 5218:2004)," (Geneva, Switzerland: ISO/IEC, 2004), www.iso.org/iso/cata logue_detail.htm?csnumber $=36266$.

34. Ibid

35. Ibid.

36. It is beyond the scope of this paper to discuss the mechanisms and systems involved in changes to the LCSH vocabulary.

37. American Library Association, "Library Bill of Rights," (statement of basic principles, 1939, reaffirmed 1996), accessed August 26, 2015, www.ala.org/advocacy/intfreedom/librarybill.

38. American Library Association, "Access to Library Resources and Services Regardless of Sex, Gender Identity, Gender Expression, or Sexual Orientation: An Interpretation of the Library Bill of Rights," 1993, amended 2008, www.ala.org/ advocacy/intfreedom/librarybill/interpretations/accesslibrary.

39. Melissa Adler, "Transcending Library Catalogs: A Comparative Study of Controlled Terms in Library of Congress Subject Headings and User-Generated Tags in Librarything for Transgender Books," Journal of Web Librarianship 3, no. 4 (2009): 309-31; Emily Drabinski, "Teaching the Radical Catalog," in Radical Cataloging: Essays at the Front, edited by K. R. Roberto (Jefferson, NC: McFarland, 2008), 198-205; Emily Drabinski, "Gendered S(h)elves: Body and Identity in the Library," Women \& Environments International Magazine 78/79 (2009/2010): 16-18; Matt Johnson, "Transgender Subject Access: History and Current Practice," Cataloging \& Classification Quarterly 48, no. 8 (2010): 661-83; K. R. Roberto, "Inflexible Bodies: Metadata for Transgender Identities," Journal of Information Ethics 20, no. 2 (2011): 56-64.

40. Drabinski, "Teaching the Radical Catalog," 198-205; Emily Drabinski, "Queering the Catalog: Queer Theory and the Politics of Correction," Library Quarterly 83, no. 2 (2013): 94-111.

41. Drabinski, "Teaching the Radical Catalog," 198-205; Drabinski, "Queering the Catalog," 94-111.
42. Frank Exner, Little Bear, "North American Indian Personal Names in National Bibliographies," in Radical Cataloging: Essays at the Front, edited by K. R. Roberto (Jefferson, NC: McFarland, 2008): 150-64.

43. Ibid, 162-63.

44. Ibid.

45. Ibid, 151-52.

46. Ibid, 152.

47. Ibid, 151.

48. Lorraine J. Pellack and Lori Osmus Kappmeyer, "The Ripple Effect of Women's Name Changes in Indexing, Citation, and Authority Control," Journal of the American Society for Information Science of Technology 62, no. 3 (2011): 440-48.

49. Nancy Silverrod et al., "TRANScending Identities: A Bibliography of Resources on Transgender and Intersex Topics," accessed November 14, 2013, www.ala.org/glbtrt/sites/ala .org.glbtrt/files/content/professionaltools/glbtrt_trans_08.pdf; Wikipedia, "Category:Transgender and Transsexual Writers," accessed November 14, 2013, http://en.wikipedia.org/wiki/ Category:Transgender_and_transsexual_writers.

50. Network Development and MARC Standards Office Library of Congress, "375-Gender (R)," accessed November 14, 2013, www.loc.gov/marc/authority/ad375.html.

51. Ibid.

52. Library of Congress, Network Development and MARC Standards Office, "375—Gender (R)"; Cristán, "RDA Special Topics."

53. International Standards Organization/ International Electrotechnical Commission, "Information Technology_Codes for the Representation of Human Sexes (ISO/IEC 5218:2004)," (Geneva, Switzerland: ISO/IEC, 2004), www.iso.org/iso/ catalogue_detail.htm?csnumber=36266; Judith Lorber, "Shifting Paradigms and Challenging Categories," Social Problems 53, no. 4 (2006): 448-53.

54. Judith Butler, Gender Trouble: Feminism and the Subversion of Identity (New York: Routledge, 1990).

55. Drabinski, "Queering the Catalog," 94-111.

56. Ibid, 106-8.

57. Ibid.

58. Program for Cooperative Cataloging, PCC Task Group on the Future of Name Authorities in a Non-MARC Environment, "Report for PCC Task Group on the Creation and Function of Name Authorities," 1-16.

59. Ibid, 13.

60. ORCID website, "What is ORCID?," accessed May 4, 2015, http://orcid.org/content/initiative.

61. Billey et al., "What's Gender Got to Do with It?"; "GLBTRT Task Force on RDA and Gender in Authority Records”; Elrod to RDA-L mailing list, February 12, 2008.

62. American Library Association Council, "Access to Library Resources and Services Regardless of Sex, Gender Identity, Gender Expression, or Sexual Orientation: An Interpretation of the Library Bill of Rights." 